\title{
BUSINESS PRESENTATIONS: AN EASY-TO-LEARN SKILL OR A NIGHTMARE?
}

\author{
Kateřina Young*
}

\section{Introduction}

Most Business English instructors at the university level face a problem when dealing with Czech college students: an "information" loaded report (in the past called "referat" in the Czech language), which is a result of the knowledge based educational system where the old "referat" still seems to prevail but has been replaced by a trendier term, called a "presentation," in a Power Point format. When faced with the "Anglo" presentation style, students often fall in despair. Their prior experience of a "presentation" stands in sharp contrast to the foreign instructors' requirements and to the demands of the current workplace. The lack of students' awareness of and skills in preparing such presentations is alarming and, therefore, the need to teach this "survival" skill becomes even more critical.

This paper reviews the findings of a questionnaire administered to the author's freshmen and sophomores with limited exposure to making presentations in English. The findings are then discussed in terms of the Czech teachers' understanding of discourse analysis and communicative competence as opposed to the Czech rhetorical tradition experienced so far by students. Consequently, effective teaching strategies, which are derived from developmental psychology, are suggested as possible ways to guide university students in successfully creating and delivering professional presentations.

\section{Importance of Business Presentations Vs. Cultural Background}

No one in the Czech environment challenges the importance of the presentation "knowhow" in the workplace. A debate over what the presentation know-how is or what a professional presentation should look like remains unanswered, specifically among freshmen and sophomores at the university level. While no one disputes that one of the major functions of a presentation is to "announce/inform," other purposes such as "to persuade/to win over/to sell," "to entertain/to relax/to set mood," or "motivate" (Pincus, 2006, pp. 3-4) have been "foreign concepts" to Czech students.

In the Czech system, the purpose of the above-mentioned "referat" has always been to "inform" others. Therefore, the emphasis has been on the knowledge and the amount of presented information. This educational tradition has required students to

\footnotetext{
* University of Economics, Prague, Faculty of International Relations (katerina.young@vse.cz).
} 
mine facts out of texts, connect them into a logical sequence, and explain what the "figure of authority," that is the author, meant to say. This strategy was widely accepted, supported, and perpetuated by the socialist system which could thus officially control what students should think. Our current students still operate in this mindset, "which includes cognitive contexts, in which past experience and knowledge is stored and drawn upon, cultural contexts consisting of shared meanings and world views, and social contexts through which both self and others draw upon institutional and interactional orders to construct definitions of situation and action" (Schiffrin, 1994, p. 4). The Czech students' mode of operation is still loyal to their past educational experience embedded in the social and cultural context of the previous regime. Therefore, this task is not only dealing with language issues but with the whole cultural tradition reflected in the use of language. This task is not teaching students to present in a different language; it is asking them to consciously switch from one cultural "persona" to another.

Regardless of the cultural background, experts on business presentations give a clear message on what it takes to succeed in today's world of business. "Knowledge of your specialty is not enough; if you can't communicate it, how much is it worth?" (Leech, 2004, p. 10). Leech $(2004$, p. 4) further discusses a variety of contexts where presentations more and more replace traditional long written documents such as Requests for Proposals (RFPs) by the bidder's team by the Source Evaluation Board (SEB) in case of pursuing a competitive bid from a government agency or a venture capitalist firm. Similarly, delivering a successful presentation can often decide the future course of a person's career or decide the fact of being hired and/or promoted. "Most of the people who rise to the top in organizations do so not only because they have demonstrated expertise in their specialties, but because they have good communication skills, particularly oral skills" (2004, p. 9). Campbell supports this fact by saying that "the number-one skill for advancement and promotions of professionals is their ability to communicate their ideas effectively" (Campbell, 2002, p. 7).

Both groups, students and their instructors, must become aware of the need for excellent oral communication skills which can not only prepare students for their future in the current workplace, but which may decide the course of their lives. Thus, instructors can become instrumental in helping students shape their future careers.

\section{The Survey}

To substantiate personal experience and classroom observations, a survey was administered to find out about students' perceptions of readiness to make and to give business presentations in English. Specifically, this survey inquired about how confident students felt in preparing and giving business-style presentations in English to an Englishspeaking/international audience in nine presentation skills areas. The survey questions were created based on in-depth interviews with the course instructors and supervisors from the Department of English (Čapková; Kusinová).

The survey was first pilot tested on a group of 22 students who were enrolled in the Spring Semester of the 2010-2011 academic year, i.e. the students' last semester of a four-semester English for Economists course. According to the Course official syllabus, the course is aimed at broadening students' vocabulary within economics 
and business, providing further training in economic text analysis and practicing all language skills - reading, writing, listening and speaking - in English. In the first part of the pilot survey, the results showed that five choices were too vague and did not show much difference between the categories of "very confident" and "confident" and between the "somewhat confident" and "not very confident" categories. Therefore, the final questionnaire collapsed these five categories into three options "confident," "somewhat confident," and "not confident." The rest of the survey followed the original questions (For the final version of the questionnaire see Appendix A).

In the third part, the pilot survey asked students to list and to rank three areas of greatest concern in order of difficulty. However, the ranking did not indicate any particular order of difficulty across the first five most commonly indicated categories of presentation skills; rather, the results spread evenly across these categories. Therefore, they indicated personal preferences of students which are not discussed in this study. Consequently, the final questionnaire asked students to list three areas of greatest concern when giving presentations without the order of difficulty. Also, to avoid misunderstanding, all categories and instructions were described in detail and possible vocabulary issues were addressed before students took the survey. The fourth question on the survey was used for the instructor's personal feedback; therefore, the results are not included in this study.

The students who participated in this survey were the author's own students in the Spring Semester of 2011. These students were selected for this survey due to their prior experience in giving presentations as part of their previous semester coursework. All of the participating students consented to fill out the questionnaires; there were no non-respondents. The first group included 64 students from Faculty of Finance and Accounting and Faculty of Business Administration, who were required to take this four-semester English for Economists course. The second group consisted of 84 students from Faculty of International Relations who were enrolled in a three-semester course of English for Business which, according to the Course syllabus, is designed to practice language skills needed for effective communication (oral and written) in various business situations, to improve students' ability to react properly, and to prepare them to perform activities such as business presentations. The two groups were similar in the level of their language proficiency in the following way: Proficiency level of students in the fourth semester of the English for Economists course assumes a corresponding proficiency level of the students in the second semester of the English for Business course. In other words, the English for Economists students usually take longer to acquire a similar level of language proficiency than their English for Business counterparts due to their initial differences when entering the University. As a result, the two groups were surveyed to find out any possible differences between the faculties and their students' presentation skills.

\section{Research Results}

Out of 64 respondents in their second semester of the English for Economists course, only 5 students, i.e. about $8 \%$, felt confident; 37 students, i.e. about $58 \%$, were "somewhat" confident and 22 students, i.e. about $34 \%$, were not confident. Out of 84 respondents in the last semester of the English for Business course, only 10 students, i.e. 
about $12 \%$, felt confident about making and giving presentations. 54 students, i.e. about $64 \%$, indicated they considered themselves "somewhat" confident, and 20 students, i.e. about $24 \%$, said they were not confident at all. Out of the total of 148 surveyed students, then, only about $10 \%$ (15 students) felt confident, $62 \%$ (91 students) were "somewhat" confident, and $28 \%(42)$ students were not confident in preparing and giving presentations.

Students, who answered "somewhat confident" and "not confident" (133 students, i.e. about $90 \%$ ), were then asked to identify the area of greatest difficulty-English language, presentation skills, both, or other (anxiety, topic, etc.). In the English for Business course, 37 students, i.e. 50\%, identified English Language as their major area of concern; 7 students, i.e. 9.5\%, marked the category of "Other," which included answers such as anxiety, topic, audience, etc. In the English for Economists course, 24 students, i.e. $40.7 \%$, claimed English Language to be the most relevant factor in their lack of confidence. Thus, 61 students, i.e. about $46 \%$, of the total number of "somewhat confident" and "not confident" students are in need of improving their English Language skills. While this number is significant, it points to the need of regular in-class practice of various linguistic structures. Teaching techniques related to this topic are discussed in Section "Critical Areas and Teaching Tips, Part B: Structure and Cohesion." A separate study may shed more light on the students' specific linguistic needs.

Nevertheless, almost an equally significant number, 65 students, i.e. about $49 \%$, stressed the need to improve presentation skills and both presentation skills and English Language. In particular, in the English for Economists course, 20 students attributed their lack of confidence to deficient presentations skills and 15 students pointed to both English and presentation skills. In total for this course, 35 students, i.e. about 59.3\%, were in need of improving their presentation skills. In the English for Business course, 22 students indicated that the major concern are presentation skills, and 8 students believed their lack of confidence is due to a combination of both their English language and presentation skills; when combined, a total of 30 students of the second course, i.e. about $40.5 \%$, perceived that presentation skills present an area of significant weakness. The findings clearly show the necessity to boost students' confidence in presentation skills in addition to enhancing their English Language skills in the classroom.

The study also looked at the first five most frequently selected categories that students have indicated in their first three choices. The English for Business course students listed the following areas as most challenging: style (47 times), outcomes/recommendations and problem-solving (36 times), structure (36 times), ability to respond to questions from audience (31 times), and sources (31 times). The English for Economists results revealed similar concerns with a slight variation in the type of selected categories. These students also marked style (34 times) and outcomes/recommendations and problem solving (30 times) as areas of their greatest concern. They also included the ability to respond to questions (27 times) as the third most worrisome category and the ability to find sources (19 times) as the fifth most problematic category. However, they added the category of audience and purpose (22 times) and placed it in the fourth position.

The fact that the English for Economists students found audience and purpose most frustrating may result from the type of the presentation task. In their first semester of this four-semester course, these students presented a product, a company, a person, 
or they found solutions to a case study or a business problem in a ten-minute presentation either on their own or with a partner. In this task, they had to clearly identify their listeners; in addition, to "hook" their audience, they were compelled to think of the reason why their listeners would want to listen to them and what they would get out of their presentation. From the instructor's point of view, it is encouraging that the students have incorporated this category into their evaluations.

On the other hand, the English for Business students only had experience with making a three-minute mini-presentation which addressed a general topic such as global warming, urbanization, recent financial scandals, etc. The purpose of this task was to formulate their own opinion, support it with evidence, and defend their position in front of the audience. While the students did include the ability to respond to questions from audience in their survey answers, they did not make the connection with a need to primarily determine their audience and purpose. This discrepancy coupled with this category's fourth rank in the English for Economists course again points to the need to make this category an absolute priority in the teaching of business presentations regardless of the presentation length and type. Once again, the traditional informative "referat" style, whose main purpose is to demonstrate a student's command of a wide spectrum of facts, still lingers in the students' minds today.

Surprisingly, both groups of students hinted at the category of outcomes/recommendations and problem solving as the second most troublesome area. This area belongs to the preparation part of the presentation which is not exposed during the actual delivery. It includes the ability to analyze and synthesize information and create a solution based on available information. This issue is directly linked with higher-order thinking skills on the scale of Bloom's taxonomy that the students struggle with due to their previous educational background which has stressed facts over personal input and creativity. This matter, however, needs further investigation and is not a subject of this study. Nevertheless, the author did not observe major problems in the above-mentioned area during the in-class student presentations. Instead, difficulties related to this area presented themselves in the organizational structure during the actual presentation, mainly in the logical sequencing of ideas and their transitioning. These results exhibit the need of a focused in-class mini-lesson on strategies to help students tackle the tasks requiring higher-order thinking skills. Due to time constraints, there is no more space to cover these skills in depth in this paper.

Generally, the areas of style, outcomes/recommendations and problem solving, ability to answer questions from the audience, structure, and sources are the most prevalent concerns indicated by the students in both groups in this survey. The area of style is closely linked with the author's category of non-verbal communication. Therefore, it is treated as the same category in this study. Except for outcomes/recommendations and problem solving, the other categories are identical with the categories that the author rendered as critical based on classroom observations.

\section{Discourse Analysis and Communicative Competence}

As mentioned earlier, it is not only students who struggle with the presentation task. The Czech instructors often do not know what exactly they should imagine under the 
term of a professional presentation and, mainly, how they should teach it! They may need to go through a "mental switch" from the old "referat" style into this pragmatic methodology which is directly linked to the application in the workplace. For this purpose, Czech teachers may need to look at the theories of "discourse analysis" and "communicative competence" to see that even this approach has theoretical linguistic underpinnings. When looking at presentations through this lense, they may open up to this methodology instead of turning it down as one of those "innovations" that they do not believe in but that they now have to teach and do not really know how.

In this sense, teachers and students should consider Deborah Schiffrin's four language assumptions which link communication with context. Schiffrin sees language always occurring in a context and being context sensitive, which means the language forms and patterns that in fact "reflect those contexts that help to constitute them" (Schiffrin, 1994, p. 5). In addition, Schiffrin sees language as always having a communicative function as it is always addressed to a recipient, i.e. to the audience. Schiffrin even goes as far as stating that it is designed for communication since "the communicative process guides the emergence and development of syntactic structures in language" (Schiffrin, 1994, p. 6). Similarly, Geaney shows that when people give a talk, they have to be sensitive to the situation, to the listener, to the purpose and other modes of communication. This is what the American sociolinguist Hymes calls "communicative competence" (Geaney, 1996, p. 9).

\section{Critical Areas and Teaching Tips}

Based on the results of the questionnaire and the in-depth interviews with the course supervisors, there are several critical areas that need improvement. First of all, there is a noticeable discrepancy between the students' own awareness of the primary need to identify audience and purpose and the focus of their actual presentations. Next, students in the English for Business course and both course supervisors identified Structure as one of their major concerns. A presentation's structure is then closely related to the amount of relevant information that students select. As brought up in the in-depth interviews and experienced by the author in her classroom practice, students often stray away from the topic and overwhelm their audience with huge amounts of irrelevant facts that they have studied on the subject instead of keeping a clear focus. In addition, students are aware of their poor presentation style and their inability to use non-verbal communication effectively. The next most feared issue for students and an equally frustrating experience for the course supervisors is the students' lack of ability to find, use, and cite appropriate sources. The last area, not included in the actual student questionnaire but explicitly stated by the course supervisors, is assessment.

Practical explanations and useful teaching strategies for the areas of presentations skills that the students and course supervisors have identified as critical are addressed separately in the seven items below:

- Audience and purpose

- Structure and Coherence

- Relevance 
- Non-verbal communication

- Responding to questions from audience

- Finding, using, and citing sources

- Assessment

\section{A. Audience and Purpose}

This is the hardest part that students and teachers have to understand. For students, two basic questions have turned out to be effective. Firstly, who is listening? Secondly, what is "in it" for the listeners? Why are they there? The communicative competence theory clarifies these two areas for teachers. It thinks of the presentation as of a speech event with the speaker taking up the role of the 'addressor' and the audience the role of the 'addressee' (Brown; Yule, 2008, p. 38). Thus, the knowledge of the addressor's own background knowledge and of the addressee's/s' expectations constitute an environment the awareness of which will be helpful for any presenter in anticipating the audience's interaction, expectations, and potential questions. Practically speaking, the following explanation by Richard Young, an American executive at a large multinational corporation, will suffice for both groups. "If the speaker does not include audience and purpose in their planning, they will be thinking of the information they know rather than of the information they are trying to convey; this leads them down the path of thinking of themselves rather than thinking of the audience, which is the goal of the whole presentation." He also mentions that the presenter will often bypass the simplest parts and put in too much information and detail instead. The presenter then gives information which the audience did not want to know or did not understand which wastes everyone's time.

In addition, another area closely related to audience and purpose is the students' awareness of stereotypical knowledge, i.e. knowledge shared by everyone in the audience. As noticed by Julie Fishman, an American instructor in the English Department at the University of Economics, Prague (VŠE), Czech students come from a homogeneous culture, and, as a result, are not used to conveying information to audiences that do not share the same background. Therefore, they often resort to "highcontext messages" in which the information that is needed to understand the context is hidden in the context that the audience is supposed to somehow already know. English native speakers are very aware of audiences with mixed levels of cultural background knowledge, linguistic proficiency, subject expertise, etc. They are used to "low-context" messages where the information necessary to understand the situation is clearly stated in the communication itself (Geaney, 1996, p. 83). Czech students need to understand this difference, prethink the potentially unfamiliar information, and adjust their presentations accordingly, respectively explain the terms their audience may not recognize.

\section{B. Structure and Cohesion}

Many current non-native English speaking instructors have struggled with structuring arguments logically in English. Most non-Anglo cultures follow the "reversed funnel" rhetorical pattern when the speaker/writer starts out very generally and slowly, and, through an exorbitant amount of information and facts, works him/herself towards the 
main idea stated at the very end. This is very confusing to an English native speaker who has been used to working like a lawyer or a scientist, stating the argument up front, then showing evidence that opposes and supports it, and eventually proving or rejecting the original point. When dealing with international colleagues in the business world, Young indicates this experience in the following way: "Sometimes I have to ask several questions just to figure out what the presentation is about, and what we are trying to decide. This is a waste of everyone's time and reflects poorly on the presenter."

To avoid this confusion, teachers need to be aware of several theoretical concepts. First of all, Halliday and Hasan (Halliday; Hasan, 1976, p. 1) define a text, written or oral, as any passage which forms a unified whole semantically, not lexico-grammatically. Therefore, even though grammar and vocabulary are important, they should not be the major focus of a presentation. Instead, the presentation should have appropriate "texture," which consists of "register" and "cohesion." "Register" refers to "a set of configurations that is typically associated with a particular class of contexts of a situation, and defines the substance of the text, including all components of its meaning, social, expressive, communicative, and so on ..." (Halliday; Hasan, 1976, p. 26). On the other hand, "cohesion" is "the set of meaning relations that is general to all classes of text and that distinguishes text from 'non-text'; cohesion does not concern what a text means; it concerns how the text is constructed as a semantic edifice" (Halliday; Hasan, 1976, p. 26).

Therefore, students find it useful when they are given specific formal phrases which help them gain access to the formal "register" in English. For this purpose, chapters on presentations from Business Vocabulary Builder (See References for further information) have proved very helpful. On the other hand, "cohesion" requires mental pre-planning of arguments, which then students need to bind together using conjunctions, i.e. specific grammatical devices for showing thematic continuity in discourse by linking one sentence with another. This is why Halliday and Hasan identify four (4) categories of these connectors (Halliday; Hasan, 1976, pp. 242-3). They are the discourse markers that native speakers listen for in order to follow the logic of a presentation. Based on the author's personal experience, these "linking" or "transitional" words need to be taught directly to students and practiced in fill-in-the-blank exercises and in students' actual writing. In-class modeling of how their long sentences are "chopped up" and, based on meaning and clarity, linked via an appropriate transitional word/phrase with another sentence is crucial for students' understanding of this process. Additional writing activities put this understanding into practice.

\section{Relevance}

Brown and Yule (2008, p. 32) hint at the notion of conversational implicature which speakers generally follow in a conversation plus four conversational conventions, or maxims, which they obey. These principles include quantity, quality, relation, and manner. When applied to presentations, in terms of quantity, students need to make their presentations as informative as required but not more than is needed; secondly, as for quality, students should not use arguments for which they lack adequate evidence; they still believe that they can "get by" without appropriately stated sources or that 
a personal opinion substitutes this evidence. Thirdly, students need to be relevant and stay on topic. Lastly, they have to be brief, orderly, and unambiguous. This last point again is a challenge for Czech students who have been led to come up with non-specific generalizations rather than clear points. Moreover, attempts at presenting information in a straightforward manner may be deemed too audacious and conceited by Czech instructors.

\section{Non-verbal Communication}

Czech students still lack the confidence to present their ideas, to stand up for their opinion, and to support it with detailed evidence. When faced with questions from the audience, they tend to look at a distant point or down on the floor. Due to their limited proficiency in English, they also like to read off the paper. If they could, they would read the whole presentation instead of actually "presenting" the information. However, Geaney (1996, p. 53) shows that it is common in Western cultures to begin interaction by looking directly at the person being spoken to. Similarly, head nods are used by the listener to encourage the speaker to continue speaking (Geaney, 1996, p. 55). When people want to convey a friendly impression, they smile a lot and lean forward to the person they are talking to. In the case of presentations, student listeners need to be guided to give support to the speaker by head nods, and student presenters need to be encouraged and periodically reminded to move around or to come physically closer to the audience instead of "being glued" to the floor in one spot in front of the projection screen. The speaker-audience interaction is the "invisible fluid" that often decides the fate of a presentation or a project. Instructors need to make sure to pass this "secret" on to their students to help them create their own comfortable, personal presentation style.

\section{E. Responding to Questions from Audience}

When taking questions from the audience, Czech students have a natural tendency not to let the speaker finish their question. As soon as they start sensing an opposing view or implied information inadequacy, they interrupt the speaker, jump in, and start countering with their argument. It is understandable when viewed from the traditional perspective of education when the student was supposed to know it all and was badly scolded or even put down by the teacher in public for "knowledge gaps" during their performance. A presentation was not meant as a two-way information exchange in form of a dialogue. Instead, it was supposed to be a never to be questioned monologue. Therefore, there is no wonder that Czech students are not able to follow several principles mentioned by McCarthy (1991, p. 127). First of all, they cannot validate the speaker's question by using "back-channel" responses of validation such as 'yeah, no, right, sure, eh-eh'; instead, these expressions are still "breaking news" to them. Also, they have a hard time with listening and being attentive to the speaker's contribution. In fact, they are not viewing the question as a contribution but as a threat. Furthermore, if the speaker talks too long when posing the question, they are unable to interrupt them politely using phrases such as "If I may interrupt" or "I wonder if I might say something." Therefore, turn-taking becomes one of the critical skills to teach to Czech students if they are to engage in meaningful professional conversations. 


\section{F. Finding, Using, and Citing Sources}

"Knowledge is Power"- this common phrase marks the entrance of many educational institutions in the United States. "Knowledge" in this sense of the word refers to "information" which can be found rather than to the traditional notion of everything that a person knows. It is the "know-how," the skills of finding information, and the ability to analyze it and use it purposefully. Research and analytical reading skills are a necessity for any successful business person or entrepreneur. Czech students enter university classes "mal-equipped" with research skills such as finding sources, analyzing and synthesizing data into a solid argument, and citing sources in the text and in final references. First of all, if they are familiar with the online search system, they have no notion of electronic sources such as e-journals in the scientific databases or e-books in e-brary. Next, they are used to taking pieces of information directly out of a source without proper citations. They use these "chunks" of text in their own paper as if this text were their own words. They may not even realize they are plagiarizing as this was a common approach in their high schools. Instead, what is asked of them now is to skim several texts, comprehend the main ideas quickly, create an argument drawn from these texts, and support it with directly cited evidence in form of in-text citations or a list of references.

To tackle the research problem, instructors need to assign students tasks which require them to go to the library and familiarize themselves with the library system and online resources. They may also employ the help of their local librarians who can serve as resources for the students and who are often more than willing to organize training for students and their instructors as in the case of the University of Economics at Prague (VŠE) staff. Therefore, a presentation with three external sources (one printed source and two e-sources from the university's databases) should be mandatory. Then, instructors need to model for students how to cite sources and create a list of References using such online resources as www.citace.com or the university's ISO 690 online guide. Additionally, they need to insist on students citing their sources according to this norm (or any other norm such as APA, MLA, etc. if used internationally for the given field).

Likewise, the Czech students struggle most in two major areas: reading texts quickly to get the most important information in a limited period of time and using the information they have read. They are excellent at the lower levels of knowledge (i.e. rote memorization), comprehension (i.e. translating information into one's own words), and application (i.e. using the information in a new situation) (Ormrod, 1995, p. 61). But analysis, synthesis, and evaluation of information, which are the three top educational objectives offered by Bloom in his taxonomy, are most difficult for them. Therefore, teachers should set clear objectives capitalizing on these three top levels of Bloom's taxonomy.

Unfortunately, English instructors do not have the time to teach all of these skills separately. However, they may be able to incorporate some of these skills into their daily activities. When reading a text from a new unit, teachers can explain such techniques as skimming and scanning (i.e. searching for main ideas and details) of the text, model it on a couple of paragraphs, and have students try it out every time they encounter a new text. They need to make their students aware of the kind of skill they practice and of the purpose for the particular activity. They need to treat their students as adults, and 
their instruction needs to reflect this level of adult cognition. When given the reasons for a particular activity and when shown how this activity will help them either in their future job or at their final exam, students are inclined to listen and become motivated to participate no matter how difficult the activity may seem. For this purpose, however, skillful layering of individual activities is vital. The activities need to be scaffolded, i.e. facilitated, by the teacher within Vygotsky's "zone of proximal development" (i.e. on a range of tasks which can be acquired with guidance of others). In this way, teachers can help modify existing schemas, or rather patterns of existing knowledge, and integrate them with new ones into Piaget's "cognitive structures" (1995, p.178). When activities are scaffolded and appropriately layered, students restructure their minds and learn to run information through new "circuits"; in this way, they acquire the new skills of analysis, synthesis, and evaluation with greater ease. The key is to design activities around a new unit text, practice these skills with this text, and make students aware of the goal. In this way, they can monitor and evaluate their own progress.

\section{G. Assessment}

Many Czech students consider the evaluation system quite arbitrary. A teacher is given a free hand at coming up with their own evaluation. Students are often given a grade without a proper explanation. Students also feel uneasy and exaggerate the value they give to a task such as a presentation out of fear because they do not know what is expected of them. While the unknown breeds fear, fear inhibits motivation, progress, and learning. Therefore, clear assessment criteria need to be announced before every task, particularly a presentation. Students then adjust their behavior and performance accordingly. In fact, "behavioral objectives facilitate the evaluation of both the student and the instructional program; when an objective is described in behavioral terms, both student accomplishment and program effectiveness can be evaluated on the basis of whether those specific behaviors are observed. From the student's perspective, behavioral objectives have an additional advantage: Students who are told what behaviors they should be able to demonstrate at the conclusion of an instructional unit have tangible goals to strive for and are better able to judge correctly their own completion of those behaviors" (Ormrod, 1995 , p. 81). While assessment criteria may differ from class to class, the fact that they need to be determined ahead of time and shared with students are an absolute must.

\section{Conclusion}

The current workplace requires excellent oral communication skills, particularly in terms of delivering effective business presentations. As VŠE prepares students to enter the global business arena, the English Language Department has also incorporated presentations into the mandatory first and second year English language curriculum. This requirement has turned out to be a "nightmare" equally for students and their instructors. Therefore, this paper has stressed the need for, firstly, understanding and, secondly, effective teaching of professional presentations in context of today's business needs. A survey administered in the author's classes has shown a significant lack of students' confidence in their English language skills and in presentation skills specific to presentations, particularly in the areas of style, ability to problem solve, ability to 
answer questions from audience, ability to find sources, and presentation structure. The results also exhibit a lack of students' awareness of the key area of audience and purpose that mandates all of the above-mentioned presentation skills. In addition, the author suggests that Czech instructors are not confident themselves about the structure and the contents of a professional presentation. Therefore, both groups, students and instructors, have to make a "mental switch" from the traditional Czech "referat" to the business "sales pitch" presentation. To help teachers "come to grips" with this difference in thinking, the author has relied on the theory of discourse analysis and communicative competence. Practical teaching tips are then suggested for the above mentioned six categories while adding the seventh area of assessment. Although the teaching strategies discussed for the afore-mentioned areas have proved to be effective for the author's students, further research with Czech students and instructors in these areas is necessary to validate the experience and observations.

\section{References}

BROWN, Gillian; YULE, George. 2008. Discourse Analysis . Cambridge (UK) : Cambridge University Press, 2008. $288 \mathrm{~s}$.

CAMPBELL, Michael G. 2002. Bulletproof Presentations: Noone Will Ever Shoot Hole in Your Ideas Again! [online]. Franklin Lakes (NJ) : Career Press, 2002 [cit. 2011-04-27]. http://site.ebrary.com/ lib/vsep/docDetail.action?docID $=10006979$.

EMMERSON, Paul. 2009. Business Vocabulary Builder Intermediate to Upper-intermediate: The words \& phrases you need to succeed. Oxford (UK) : MacMillan, 2009. $176 \mathrm{~s}$.

GEANEY, Declan. 1996. Discourse Analysis and Related Topics for Teachers of English As a Second Language. Praha : Karolinum, 1996. $153 \mathrm{~s}$.

HALLIDAY, M. A. K.; HASAN, Ruquiya. 1976. Cohesion in English. London (UK) : Longman, 1976. 374 s.

LEECH, Thomas. 2004. How to Prepare, Stage, and Deliver Winning Presentations [online]. 3rd edition. New York (NY) : American Management Association, 2004 [cit. 2011-04-27]. http://site.ebrary. com/lib/vsep/docDetail.action?doclD $=10052852$.

MCCARTHY, Michael. 1991. Discourse Analysis for Language Teachers. Cambridge (UK) : Cambridge University Press, 1991. $213 \mathrm{s.}$

ORMROD, Jeanne Ellis. 1995. Human Learning. Englewood Cliffs (NJ) : Prentice-Hall, 1995. $608 \mathrm{~s}$.

PINCUS, Marilyn. 2006. Boost Your Presentation IQ [online]. New York (NY) : McGraw-Hill, 2006 [cit. 2011-04-27]. http://site.ebrary.com/lib/vsep/docDetail.action?doclD=10131966.

SCHIFFRIN, Deborah. 1994. Discourse Markers. Cambridge (UK) : Cambridge University Press, 1994. $364 \mathrm{~s}$.

VŠE. 2011. Sylabus předmětu 2AJ204 - Angličtina pro ekonomy - pokročilá úroveň 4 (FMV - LS 2010/2011) [online]. Last revision February 23 ${ }^{\text {rd }}, 2011$ [cit. 2011-04-27]. https://isis.vse.cz/auth/ katalog/syllabus. pl?predmet $=73362$.

VŠE. 2011. Sylabus předmětu 2AJ352 - Angličtina v obchodě a podnikání II (FMV - LS 2010/2011) [online]. Last revision January 4th, 2011 [cit. 2011-04-27]. https://isis.vse.cz/auth/katalog/syllabus. pl?predmet $=73362$.

Personal Interviews

ČAPKOVÁ, Halka; KUSINOVÁ, Martina; FISHMAN, Julie. 2011. Personal Interview. April 27, 2011.

\section{Personal Email Communication}

YOUNG, Richard J. 2011. Paper Questions. Young, Kateřina. Personal email. April 2, 2011. 2:28 pm. [cit. 2011-4-25]. 


\section{BUSINESS PRESENTATIONS: AN EASY-TO-LEARN SKILL OR A NIGHTMARE?}

Abstract: Most Business English instructors at the university level face a problem when dealing with Czech college students: an "information" loaded report, which is a result of the knowledge based educational system where the old "referat" still seems to prevail but has been replaced by a trendier term, called a "presentation," in a Power Point format. When faced with the "Anglo" presentation style, students often fall in despair mentioned above. Their prior experience of a "presentation" stands in sharp contrast to the foreign instructors' requirements and to the demands of the current workplace. The lack of students' awareness of and skills in preparing such presentations is alarming and, therefore, the need to teach this "survival" skill becomes even more critical. This paper reviews the findings of a mini-survey administered to the author's freshmen and sophomores with limited exposure to making presentations in English. The findings are then discussed in terms of the Czech teachers' understanding of discourse analysis and communicative competence as opposed to the Czech rhetorical tradition experienced so far by the students. Consequently, effective teaching strategies, which build on developmental psychology research, are suggested as possible ways to guide university students in successfully creating and delivering professional presentations.

Keywords: business presentations, English for Specific Purposes, Business English, business communication

JEL Classification: P300, I290, M140, Z000, O150

\section{APPENDIX A}

Questionnaire

1. How confident do you feel about giving a business presentation in English to an English-speaking/ international audience?
A. Confident
B. Somewhat Confident
C. Not confident

2. If you answered $B$ or $C$ in the previous question, please specify the reason (indicate all that apply):
A. English
B. Presentations Skills
C. Other-please explain

3. Please list your three areas of greatest concern when giving presentations:
A. Keeping in mind audience and purpose
B. Structuring your presentation - I. Logical organization
II. Appropriate links/transitions from one idea to the next
III. Use of examples
C. Outcomes/Recommendations-Summary of how the results will benefit the audience $\mathrm{OR}$
Problem-Solving — Suggesting your own solutions to the issue based on evidence you have collected
D. Style-Talking off the top of your head, loudly, confidently
E. Pace-Not too slow, not too fast-setting your own comfortable pace
F. Time-Selecting the most important information to keep the time limit
G. Sources-Finding sources, citing references
$\mathrm{H}$. Ability to respond to questions from the audience
I. Ability to use external sources and use them to support your opinion

4. How much did your class cover and explain the points in question 3?
A. Most or All of them
B. Some of them, but not in depth
C. Hardly any or did not cover or explain them at all 